\title{
JOM TECHNICAL TOPICS
}

JOM: The Journal includes peer-reviewed technical articles covering the full range of minerals, metals, and materials. TMS members receive free electronic access to the full library of TMS journals, including JOM. For the full Editorial Calendar, visit wwww.tms.org/EditorialCalendar.

Review the technical topics included in the current issue of JOM: The Journal here, and then go to wwww.tms.org/JOM to log in access technical journal articles on the Springer website.

\section{JANUARY 2022}

\section{IR in Extractive Metallurgy}

Scope: With the advent of the fourth industrial revolution, advanced digital technologies that facilitate engineering, design, optimization, and management are becoming increasingly pervasive across a wide range of industries. In extractive metallurgy, large processing plants often combine many unit operations together into highly complex and interdependent flowsheets, making them a rich field for potential application of 4IR technologies. This topic will explore past, present, and future research and development into the use of 4IR in the extractive metallurgy.

Editors: Chris Aldrich, University of Stellenbosch; Quinn Reynolds, Mintek; and M. Akbar Rhamdhani, Swinburne University of Technology

Sponsor: Pyrometallurgy Committee

\section{Advanced Functional and Structural Thin Films and Coatings}

Scope: This special topic encompasses all aspects of advanced thin films and nanomaterials for modern optical, photonic, and electronic devices with applications in photovoltaics, sensing, and display technologies. It also addresses coating technologies and surface structuring for tools, as well as multifunctional biomaterials, innovative approaches to new concepts, and applications.

Editors: Ramana Chintalapalle, University of Texas at El Paso; Adele Carrado, Strasbourg University; Gerald Ferblantier, Strasbourg University; Karine Mougin, CNRS - IS2M; Heinz Palkowski, Clausthal University of Technology; and Nuggehalli M. Ravindra, New Jersey Institute of Technology

Sponsor: Thin Films and Interfaces Committee

\section{New and Novel Laboratory and Pilot Techniques for Pyrometallurgy}

Scope: Laboratory and pilot testing is critical for advancing our understanding of pyrometallurgical processes. Due to advances in analytical techniques and our understanding of pyrometallurgy, laboratory, and pilot testing is advancing as well. This topic focuses on describing new and novel piloting and laboratory techniques, illustrating their use and the advances that have been made.

Editors: Stuart Nicol, Glencore Technology, and Will Hannemann, Glencore Technology

Sponsor: Pyrometallurgy Committee

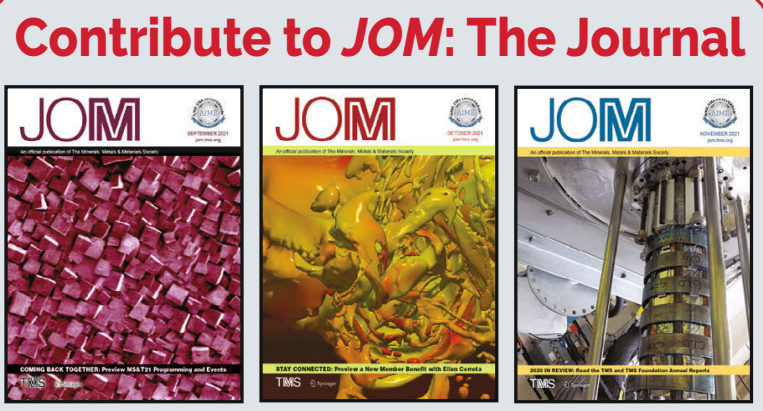

Visit www.tms.org/JOM to access author tools that will answer your questions during every step of the manuscript preparation process, from determining the appropriate technical topic for your paper to reading the final product on SpringerLink.

For further information on contributing to JOM, contact JOM Editor Maureen Byko at mbyko@tms.org. 